each other over the whole surface of the entire field. It was a glory not to be forgotten. This year not a plant of the species is visible riding past. Scattered daisies, golden rod (not $S$. nemoralis), a few $Q E$. biennis, and an occasional lespedeza ( $L$. capitata) are all that show. The ground is very sparsely covered, whereas last year it was completely occupied, as indeed also by the daisies, the œnothera, and the golden rod in their respective years.

I am satisfied the same thing takes place on other unoccupied sandy fields about here, but I have not watched them as closely nor as regularly as this one. M. W. V.

Fort Edward, N. Y., July 29.

\section{WORMS ON THE BRAIN OF A BIRD.}

To judge from Professor French's communication under this title in the current volume of Science, p. 20, he is unacquainted with the description and figures of the threadworm of the snake bird given by Prof. Jeffries Wyman, in 1868, in the Proceedings of the Boston Society of Natural History, Vol. 12, p. 100. Saviuel H. Scudder.

A space-relation of Numbers.

The recent notes and discussions as to certain curious relations observed by some persons between sensations of color and of sound,-relations hardly conceivable by others who, like myself, have never experienced them,have led me to reflect upon a peculiar conception of my own, which may be called a space-relation of numbers. I have never heard it alluded to by any one; but it has been constant with me since childhood, and seems so peculiar and inexplicable that it may be worthy of mention and inquiry. It is presented, therefore, in the hope that the experience of others may throw some light upon it as a mental phenomenon, and help to show whether it be a mere idiosyncrasy or an experience at all known, and, if the latter, how far familiar, and with what, if any, modifications.

My first distinct recollection of this idea goes back to the age of nine or ten years, in connection with learning: the multiplication table. This I was taught, not at school, but by home instruction, and without any use of cards, tables, slates, abaci, or any visible signs or aids whatever. It was purely abstract and memoriter. Somehow, then, and ever since, the numbers from 1 to 100 have been conceived of by me as holding, relatively, definite positions in space, from which they never vary,- - the mention or use of the number being at once associated with its position relative to other numbers, in the same way that the mention of a well-known country or river brings up a mental picture of its geographical location.

This numerical position has no relation with that of any other object or thing, nor with the position of the body or the points of the compass. In describing it, however, I must employ the latter, but simply as aids, in place of a diagram. The numbers, which are conceived of merely as points or stations in space, appear to be arranged in a peculiar line or lines in a horizontal plane. Beginning with unity, the series runs in a straight line to 20 , where it turns ninety degrees to the right, and so goes to 30 . Using the points of the compass merely for the present description, as above stated, and not from any connection with the number-scheme itself,--if the series 1-20 runs (say) northward, 20-30 runs always east, 20 being the apex of the right angle. From 30 to 40 the course is reversed and runs back westward; at 40 it again turns at a right angle and proceeds south, without interruption, to 90 , where the line again turns east from 90 to 100 . Above this point, the numbers have the same positions again, and so in each succeeding hundred; so that the same description applies to all.
It will be seen by any one who attempts to put this scheme on paper, that, according to the arrangement, the numbers 30 to 40 would coincide, in reverse order, with 20-30, 40 falling upon the same spot as 20; while 40-60 would coincide with 1-20, in reverse order. But in the mental conception this is not the case. The line 30-40 seems parallel to $20-30$, but at some little distance; and a vague sense of space, gradually increasing until no distinct relation is consciously noted, prevents any approach or interference between the numbers above 40 and those below 20. This fact confirms the impression that the idea is not due to any artificial aid in the way of diagram, table, or the like, in childhood.

The only suggestion that occurs is found in the fact that about that period the family had lived for some time in a large hotel (the Delavan, at Albany), whose corridors and numbered rooms may have impressed themselves on the child-mind in some such way. But I distinctly recall that certain of those rooms, occupied at different times by the family, did not at all have the positions that their numbers hold in this mental scheme.

Be this as it may, however, the clearness and the persistence of this association are remarkable, and I should be greatly interested to know if others can report any similar experience. If certain chords in music can suggest the sensation of purple, or the sound of a word a corresponding impression of blue, etc., as apparently is the case with some persons, why may not certain abstract numbers have similar associations of space-position?

New York, Aug. 3 .

D. S. MaRTin.

Preliminary note on the cottony Scale of the Osage Orange.

IN June I found a Cottony Scale (Pulvinaria) in some abundance on an osage-orange tree (maclura) in Las Cruces, N. Mex. The young were hatching on and about June 14th. This scale would be referred by modern entomologists to Pulvinaria innumerabilis (Rathvon) Putnam, but finding that it did not agree very well with published accounts of that species, I sent to Professor Bruner for specimens of the true insect, which abounds at Lincoln, Neb. Professor Bruner very kindly forwarded without delay a number of examples from box-elder, which were evidently not quite the same as my osage-orange scale.

The box-elder scale, however, agrees with innumerabilis, while the maclura scale is what was formerly named maclurce, and afterwards sunk as a synonym of innumerabilis.

The most conspicuous and constant difference is in the size. In order to show this, I boiled the adult females (which had formed ovisacs) in caustic soda, and spread their skins flat on a glass slide. Thus treated, the measurements were as follows:

P. maclurae (Las Cruces) . . length 10, breadth $10 \mathrm{~mm}$.

P. innumerabilis (Lincoln) . . " $7 \frac{1}{2}$, " 5 "

It is thus seen that maclurae is both larger and broader in proportion; and no intermediate specimens were found. Another difference is in the length of the fourth joint of the autenna: in the Las Cruces maclurae it is about as long as the third joint, whereas in the Lincoln innumerabilis it is decidedly shorter than the third. I have not yet examined enough specimens to make sure if this character is invariable. I do not wish to assert positively that $L$. maclurae is a valid species, but its characters are such as have been held to distinguish species of Pulvinaria in Europe. I hope to set the matter at rest hereaiter by the examination of more extensive material, but it must be admitted at least that it is a very distinct race or variety. In this we revert to the original opinion of Fitch, Walsh and Riley $(1855,1860,1868)$, which has been set aside for so many years. 
In order to be sure that I had rightly identified the two forms, I sent specimens to Professor Riley. He at once replied: "You are perfectly correct. A. [this refers to the lettering of the specimens] is the form which I described as Pulvinaria maclurae, while $h$. is identical with typical specimens of Pulvinaria innumerabilis on maple."

It appears that Robert Kennicott was the first to suggest the name maclurae, and Fitch to publish it. This was in the Country Gentleman, Jan. 18, 1855. In 1868 Messrs. Walsh and Riley published another description of the osage orange scale, also using the name maclurae. Those who do not consider the Country Gentleman a proper medium for scientific description may cite Walsh and Riley as nomenclators. If this should be done, it would seem that innumerabilis Rathv., published in the Pennsylvania Farm Journal, 1854, has at least no better standing, in which case Fitch's name acericorticis, given in the Trans. N. Y. Agric. Society, 1860, should be employed, or if it be insisted that the description must appear in a purely scientific publication, we must fall back on acericola, Walsh and Riley, 1868! For my own part, I would use the earliest name in each case, but one must allow that this is a matter for legitimate differences of opinion.

Thus we have-

(1.) Pulvinaria innumerabilis, Rathv., 1854. The Cottony Scale of the Maple.

$=$ acericorticis, Fitch, 1860 .

= acericola, W. \& R., 1868

(2.) Pulvinaria maclurae, Kenn. MS., Fitch, 1855. The Cottony Scale of the Osage Orange. - maclurae, W. \& R., 1868.

It need hardly be pointed out that the separation of these races or species is a matter of some interest to economic entomologists.

T. D. A. Cockereli.

Las Cruces, N. Mex., July 29, r893.

\section{EXPLOSIVE Gas IN HOT WATER APPARATUS.}

IN the hot water apparatus, used in heating houses, it is well known that gas or "air" accumulates from time to time. This is let off from the radiators where it may collect by turning the "air" tap provided; otherwise the accumulation under ordinary circumstances would interfere with the circulation of water through the pipes. Being curious as to the nature of this gas, on a certain occasion I smelled it when escaping from the tap, and detected a peculiar odor of what I took to be a hydrocarbon compound. Collecting some of the gas, I cautiously applied a light to it, which produced an explosion.

The furnace was a small, upright one, with the water heated between its double walls, large enough to warm in winter time a house of seven or eight ordinary rooms. Anthracite coal was used.

With a larger upright furnace, having tubes for the smoke and heated gases to pass through in its upper part, in addition to the water-filled sides of the first, the amount of gas collecting in the highest radiator in the house was more abundant, especially when anthracite was used instead of bitumenous coal, for which the furnace was also adapted. As a matter of fact, several litres of gas were produced each week in two neighboring houses supplied with this latter style of furnace, during the period of observation,- - a few weeks during last winter.

A considerable quantity of the gas was collected for demonstration before a popular meeting of the Institute of Science. Jars of various sizes were filled with the gas, which was burned under various conditions. 1st-The peculiar odor of the gas was tested. 2nd-It burned in the jars when inverted, and otherwise very much like pure hydrogen, giving forth very little light, but much heat. 3rd-The products of combustion showed no trace of carbonic dioxide which could be detected by the lime water test, which was sensitive enough to detectits presence in the room from the respiration of those present. From this it was inferred that neither carbon monoxide nor a hydrocarbon could be present in any considerable quantity. 4th-Pure nitrogen dioxide injected into the gas gave no ruddy discoloration. Hence, there was no oxygen in the gas. 5th-When mixed with air it would explode like air and hydrogen. 6th-It was not convenient at the time to apply any other tests, or any very accurate ones. The impression was formed that the gas must be nearly pure hydrogen.

If it was nearly pure hydrogen it must have come from the decomposition of the water, which would apparently imply a corresponding oxidation of the iron piping or of the heated iron in contact with the water within the furnace. The greater abundance of the gas when anthracite was used suggested that the origin of the gas was the rapid oxidation of the water tubing within the furnace when the heat was particularly intense. If so, every litre of hydrogen produced would mean the conversion of over one and a half grains of metallic iron into "rust."

Again, if a lighted match should be applied to the tap when this gas (pure) is being allowed to escape, the jet would catch fire and "roar" with a hot, bluish flame, of dimensions as terrific as the bore of the tap would allow. As by the "boiling over" of the furnace the small tank and upper coils ander some conditions of water pressure may be emptied and filled with air, what would the consequences be were the mixed gases allowed to escape at night with a lamp held in the hand carelessly near such a jet?

The discussion of these demonstrations revealed the fact that no one present ever knew or heard that the gas escaping from radiators might be explosive-not even the builders, plumbers and founders.

Query 1. Is the formation of explosive gas within the hot water apparatus of our houses rare, peculiar to certain furnaces, or is it common?

Query 2. Has an accurate analysis of such gas been made; and if so, what are its constituents?

Halifax, N. S. A. H. MacKay,

MINERAL WAX.

IN Science of July 14th, page 25 , I notice an article on "Mineral Wax," from which the following is an extract: "In the United States it (mineral wax) is mined in situ at Soldiers' Summit, Uintah County, and in Nmery County, Utah." Permit me to state that Soldiers' Summit of this Territory is in Utah County ; that mineral wax or ozocerite is not mined at Soldiers' Summit, nor in Uintah County, nor in Emery County, Utah. I greatly regret to have thus to correct the writer of the aforesaid article, for it would be an especial pleasure to me to be able to report mines and mining of ozocerite from Utah. I think a small quantity of it occurs in Emery County. But it is not yet mined. Of course, it may occur in large quantity in Utah, but up to the present time no satisfactory evidence of such occurrence has been presented. It is, however, possible at present to report ample and satisfactory evidence of the occurrence in Utah of large quantities of three related hydro-carbons, viz.: wurtzillite, uintahite and asphaltum. Of these, the first has not yet been mined; but the second and third are being mined with some degree of activity.

Uintahite, often called Gilsonite, after a resident prospector and miner in this vicinity, yields black varnish. It is very light, being only a little heavier than water. Its color is black, and its streak is brown or reddish-brown. It possesses a brilliant, shiny lustre, and has a perfect conchoidal fracture, like that of glass, quartz and obsid- 